DOI: https://doi.org/10.47405/mjssh.v5i11.543

\begin{tabular}{|c|c|}
\hline 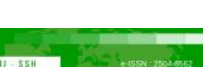 & Malaysian Journal of Social Sciences and Humanities (MJSSH) \\
\hline Malaysian Journal of & Volume 5, Issue 11, November 2020 \\
\hline (Mu-ssH) & e-ISSN : 2504-8562 \\
\hline & $\begin{array}{l}\text { Journal home page: } \\
\text { www.msocialsciences.com }\end{array}$ \\
\hline
\end{tabular}

\title{
An Assessment of the Implementation Impact of SURE-P Intervention on Maternal Mortality in the Selected Local Governments in Niger State, Nigeria
}

\author{
Abubakar Mohammed Jibrin'1, Azmil Muhammad Tayeb' ${ }^{1}$, Siti Zuliha Razali1 \\ ${ }^{1}$ School of Social Sciences, University Sains Malaysia (USM) \\ Correspondence: Abubakar Mohammed Jibrin (abubakarjibrinkutigi@gmail.com)
}

\begin{abstract}
The objective of this study was to explore the implementation of the SURE-P intervention on primary healthcare among the selected local government areas of Niger State, Nigeria. In these local governments, the primary health centers are not enough, and the existing ones are dilapidated with the absence of facilities needed to operate effectively. To access medical services, some communities must travel long distances, resulting in high mortality rates. This study examined the perceptions of Desk Officers regarding implementing the SURE-P intervention in primary healthcare among the selected local government. A descriptive design within the qualitative tradition was used in the Study. Thirteen SURE-P desk officers from the state and selected local governments were purposively selected as participants for this study. Semi-structured interviews were used to collect data, and a thematic framework was used for interpretation. The results revealed that the primary healthcare SURE-P initiative had improved access to medical facilities across the selected local governments, resulting in a slide reduction in maternal motility. Furthermore, there was a lack of adequate assessment of needs, insufficient funding, relatively low inclusion, and political pressure in the implementation process. Based on findings, it is recommended that the SURE-P intervention be sustained, adequately financed, that the community members' priority needs should be addressed, that the community members should be more inclusive, and track the implementation of the SURE-P intervention.
\end{abstract}

Keywords: SURE-P, interventions, maternal mortality and local government

\section{Introduction}

An estimated 303,000 maternal deaths occur per year worldwide due to factors related to pregnancy and childbirth. In developing countries, about 99 percent of these deaths occur, and nearly half of the maternal deaths (44 percent) occur in sub-Saharan Africa. Maternal death can result from complications that may occur while pregnant, during childbirth, or after delivery. The number of women who die from these avoidable causes is greatly decreased by enough access to primary health centers and birth planning and related health issues ahead of time.

It has been reported that Nigeria has the world's second-highest rate of maternal mortality. Nigeria accounts for around $14 \%$ of the worldwide maternal mortality rate and people who die during childbirth, next to India. While these staggering numbers are worsening in all areas of the world, many lines of evidence suggest that most maternal deaths arise in the geopolitical regions of the northeast and northwest, where people have the difficulty of inadequate access to functional maternal and neonatal health facilities. The SURE-P healthcare initiative's goal is to recognize the barriers stopping women 
from using primary health care in Nigeria for maternal and infant care and to test creative and community-based approaches to increase women's access to primary health services to reduce maternal deaths.

According to Yaya et al. (2018), Nigeria's current maternal mortality rate is 545 to 608 per 100,000 births, among the world's highest. Nigeria was categorized in a Lancet publication as one of six nations accounting for 50 percent of global maternal deaths. The country's approximate 40,000 maternal deaths are the world's second highest and account for one-third of all maternal deaths worldwide, along with India. In Nigeria, the childbirth incidence is 42 per 1000 and the world's second highest and is one of ten countries accounting for up to 66 percent of stillbirths worldwide. The World Health Organization (WHO) suggests growing women's access to upgraded reproductive health care facilities as a significant initiative to enhance maternal health in developed countries. This is due to research demonstrating that the strongest maternal health metrics mostly occur in countries with the highest specialized maternal health services rate.

\section{Theory Framework}

This paper focuses on the ideology of neoliberalism, a political doctrine advocating global liberalization, open trade, and efficient economies, globalization, redistribution, and a weakening of the public sector, thereby increasing private sector involvement in the civilized world. Over time, the concept of neoliberalism has changed, as multiple sects have come to mean different views. Nevertheless, it is quite hard to explain. It can be seen in the fact that academic studies on neoliberalism, like Hayek (2006) and Harvey (2005), do not support the notion of neo-liberalism. When defining an impartial and unambiguous definition of neo-liberalism, this absence of consensus poses crucial issues.

In the first place, neo-liberalism is the theory of political-economic practice, which suggests that the best way to promote the quality of life of people is to liberate entrepreneurial freedoms and skills within an institutional structure controlled by substantial private property rights, free markets, and free trade (Harvey, 2005). This refers to policies and practices that enable many private corporations to control social life to exploit their benefit (Chomsky, 1999).

Since participation in classical liberalism had declined in Europe, European liberal schools embraced the term in the mid-30s to promote a new liberalism model. In the decades that followed, bourgeois ideology appeared to contrast with classical liberalism's more laissez-faire philosophy, which advocated a capitalist economy, a framework centered on the social market process, within a federal state's rules and regulations. The usage of the word "neoliberal" deteriorated drastically in the sixties. The definition changed in the decades that followed, as the term was re-introduced. The word neoliberal is often generally identified with the strategies of economic laissez-faire and is used by those who are highly critical of government sector reform (Boas \& Gans-Morse, 2009).

The term "neo-liberalism" was first invented by Walter Lippmann's German scholar Alexander Rustow at the Colloque in 1938. The colloquium established the philosophy of neoliberalism as a topic on the price system, free markets, the competitive framework, and a strong and impartial policy (Mirowski, 2009). Over the past few decades or so, the word has become a form of exhortation in several political and scholarly discussions.

It tends to be the condition of writers who use the term representing what they perceive as the shameful spread of capitalism and consumerism and, therefore, the similarly disdainful displacement of socialstructure behavior. (In particular: Bourdieu, 1998; Chomsky, 1999; Touraine in 2001; Hermansen, 2005; Saad-Filho in particular et Johnston, 2005; Hagen, 2006; Plehwe et al. in particular).

Ideology proposes its concept: 'neo-liberalism' is a resurgence of 'liberalism.' This implies the disappearance from popular discourse and decision-making of liberalism as a decision ideology for a time to only return in a more fresh and re-rising manner. In other words, it shows that liberalism has 
experienced an early transition, an abrupt turnaround, and finally a new revitalization. Neo-liberalism may also be a distinct, standard-liberal philosophy that doesn't like it. Neoliberalism will share its historical origins and some basic language with liberals. Understand neoliberalism within the same category as American neo-conservatism, an attitude to philosophy or constitutional system is very similar yet quite different from many typical conservative values and, therefore, not recognizable as a true conservationist movement. (Kristol; 2004; Wolfson; 2006).

Under Chile's military dictatorship of Augusto Pinochet (1973- 1990), opposition intellectuals repeatedly took over the notion without any loosely linked theoretical revision of liberalism. In Chile, instead, there have been many political and economic reforms, and the word has been embraced with pessimistic connotations (Boas \& Gans-Morse, 2009). Neoliberalism is never really described but is used, according to the Boas and Gams-Morse review of 140 journals in the past decades, in various forms, to describe economics, economic theory, the ideology of progress, or the agenda for economic change. In no small point, it was a term of condemnation used by opponents of economic innovation liberalization.

The early neoliberals' ideas suggest market fundamentalism as the laissez-faire ideals of the pale liberals. In social sciences, this creates some confusion regarding the term's exact meaning and value, particularly when the amount of different consumer economy forms in recent years has multiplied.

Boas and Gans-Morse (2009) assert that by way of privatization and fiscal consolidation, neoliberalism through internal transition strategies such as eliminating price caps, deregulation of financial markets, and growing trade barriers and state intervention with the economy was more widely utilized today. The concept is used as an ideology and is mainly closely related to neoclassical and academic structures to describe democracy as an overarching social value related to reducing the state's role. Some claim that the word is a derogatory expression for initiatives to deregulate the private sector and boost its economic status.

\section{Neo-Liberalism Main Doctrines}

The central concepts of Neo-liberalism include:

Market Rule: This means freeing all business or the private sector from government bonds regardless of society's consequences. Reduction of government expenditures on social services, including education and health, housing and infrastructure. The safety net for the poor includes public works, infrastructure, construction of bridges, water supply, and conservation of the environment and sanitation to limit government interference.

Effective macroeconomic policy: with what may be related to as "strong macroeconomic dynamics," the need to maintain secure, predictable markets and steady real interest rates. Which involves strict monetary and fiscal strategies to protect budget deficits and resources.

Commercial liberalization: trade must be liberalized to improve foreign competition by cutting tariffs and other hurdles and freeing up currency exchange rates.

Privatization: The state's need to withdraw control or management responsibilities from economic activities carried out by the private sector through transferring from the state to the private sector. Neoliberals were often able to limit regions that are perceived to be legitimate government operations dramatically over time, thus widening privatization regions. For example, in areas such as health, education, water supplies, environmental protection and sanitation defense, and certain routine administrative functions such as registration, collecting charges, issuing fines, etc., the areas that require privatization have been gradually identified.

Deregulation: The need to remove any legislation that might impose obstacles or restrictions on the movement of goods and services, on capital, on the state created by them, and on the regulatory structure necessary for the functioning of the economy and the protection of land rights and contracts. 


\section{The theory Application to the Study}

The ideology of neoliberalism is an approach to economic and social studies that shift economic forces from the public to the private sector. Since neoclassical economics assumptions are taken, neoliberalism means that governments raise capital investment, abolish subsidies, adjust tax laws to strengthen the tax base, reduce fixed exchange rates, expand trade markets by restricting protectionism, privatizing state-owned companies, encouraging land ownership and deregulation.

Neo-liberalism refers to economic policies such as the "repression of price controls, restructuring of capital markets and the removal of trade barriers" and the abolition of the economic position of the state, especially through privatization and fiscal austerity (Boas \& Gans-Morse, 2009). The scientific inference is that the most controversial issue today in Nigeria is the deregulation of oil products (one of neoliberalism's principles).

According to Onyishi, Eme, and Emeh (2012), the discussion on the removal of oil subsidies acquired traction in January 2012, after the Senate, which is Nigeria's highest legislative entity, approved the downstream reform of the oil \& gas market, a significant part of the Petroleum Industry Bill (PIB). The removal of fuel subsidies by the Federal Government, which was a deliberate strategy aimed at maintaining and leveraging Nigeria's oil resources, generated cries among Nigerians of frustration, apprehension, and concern, leading to a mass protest. In reaction to Nigerian demands, the President declared that the Subsidy Reinvestment and Empowerment Program (SUREP) would reinvest a portion of the savings arising from the Federal Government's elimination of subsidies, as is shown in one of the neo-liberal doctrines (Security Net Provision for the Poor: road maintenance, water source bridges, primary health, and schooling, etc.). The policy also guarantees that some of the savings from removing fuel subsidies from the Federal Government were aimed at vital infrastructure projects and social safety net services that would directly relieve Nigerians' misery and mitigate the effects of reducing subsidies.

\section{Literature Review}

In January 2012, the partial abolition of fuel subsidies by the Government of Nigeria culminated in the creation of the Subsidy Reinvestment and Empowerment Program (SURE-P) to enable productive use of the accrued revenues (Amakom, 2013).

Akinola (2018) argues that the share of petroleum savings of Nigeria's federal government has been invested in social safety nets, infrastructure, and human development programmes to enhance Nigeria's economy and alleviate poverty. The federal government has invested part of its subsidy savings in SURE-P 's Maternal and Child Health $(\mathrm{MCH})$ to improve maternity and child survival. The National Primary Health Care Development Agency developed this portion of SURE-P through the Program Management Unit (PIU) located in FCT-Abuja, emphasizing the Agency's existing Midwife Service Scheme (MSS). According to Ikpeazu (2018), The MSS helped to organize and deploy women's parenting to designated primary health centers around the country to improve access to effective maternal health centers.

Trained midwives and community health extension personnel have been sent via SURE-P MCH initiatives to specific facilities in the 36 states of Nigeria. The FCT and health care groups have been strengthened across healthcare facilities (Oduenyi, Ordu, \& Okoli, 2019). For the successful operation, medicines, consumables, and infrastructural changes such as the renovation of primary health centers and the provision of boreholes to improve access to potable water have also been implemented. Besides, SURE-P 's MCH used the conditional cash conversion scheme as a powerful stimulant for the demand for MCH services (Okoli et al., 2014). However, the SURE-P CCT MCH project was initiated to verify if extra cash compensation would substantially affect the usage of pre-natal care and childcare services. After a six-month proof of design, the SURE-P MCH CCT project was officially unveiled at the Deidei Comprehensive Health Center in Bwari, Bwari Area Council Abuja-FCT on 13 May 2013. 
Onokerhoraye et al. (2014) believe that in low-resource communities, the way to expand access to Skilled Birth Attendance (SBA) is to strengthen primary health care (PHC). Several reports have shown that lack of money to pay for health facilities, travel problems, impressions of derogatory views of health personnel, and lack of approval from husbands and other family members are the main factors why mothers do not use maternal health care PHCs. In 2006, a document called 'Accelerating the Achievement of MDG 5' from the Nigerian Presidential Committee identified high rates of poverty and the inability to afford health services as major obstacles to women's access to quality maternal treatment (Yaya et al., 2018). The Federal Ministry of Health announced in 2007 that state governments could implement policies that provide free maternal and child health facilities to address financial obstacles. The Nigerian Primary Health Care Development Agency (NPHCDA) has also created a Midwives Services System (MSS) for dealing with the supply problems associated with the absence of practitioners at primary health centers throughout the world, with the aim of recruiting PHCs for maternal care in under-served areas. By 2010, reports suggest the establishment of free maternal and child health facilities by 18 out of 36 Nigerian countries.

(Yaya et al., 2018) stated that the NPHCDA reported in December 2012 that about 2,500 sister-friends were employed to work in PHCs in rural, under-served communities in Nigeria. The conclusion of many jurisdictions, such as free maternal care, is that although this has not been sustained over time, health care in some areas has temporarily increased. Many health practitioners and women voiced frustration because many health centers were without essential services despite the light of free healthcare. Health care workers were improperly motivated, while many of the pre-existing conditions contributed to low use persisted. There is evidence that maternal mortality is significantly increased when unqualified siblings are provided, as those who die during labor or are subject to perinatal mortality mainly are those who are not being treated for antenatal, intrapartum, and postnatal and those whose births have been taken or delivered by a non-qualified birth attendant in their homes (Mercer et al., 2006). Global demographic and health study figures reveal that less than $65 \%$ of Nigerian women receive prenatal drugs during pregnancy, less than $33 \%$ receive preparation for birth attendants when delivered, and less than $40 \%$ receive postnatal treatment.

Enfield (2019) opined women in Nigeria typically have lower literacy levels relative to men and are less interested in the workforce, he added. They live five years longer than the average women in SubSaharan Africa and die 18 years earlier than their average women.

Around 53 percent of the population of Nigeria resides in rural areas (Akpan, 2012). Filippi et al. (2006) mentioned that women are at higher risk for adverse reproductive health effects in rural communities, such as maternal mortality. Urban bias in the proximity of health services and the shortage of skilled human capital for health exacerbate rural women's reproductive health issues. (Kim, Singh, Speizer, Angeles, \& Weiss, 2019). In comparison, women in rural Nigeria make far less use of comprehensive maternal healthcare services than their urban peers. Only over $21 \%$ of rural women have access to maternal services, compared with $29 \%$ in urban centers. (Adewuyi et al., 2018).

According to Dahiru and Oche (2015), In 2013, while 84\% of urban women sought an ANC, only 47\% of rural women sought an ANC. Modern contraceptives are often used less by rural women and have a greater abortion rate and serious complications of illegal abortion than their urban counterparts in urban centers. Only 6 percent of rural women in Nigeria used modern contraceptives. In 2003, 26 percent of rural women than 22 percent of urban women who sought care after an illegal abortion had serious complications (Lamina).

Carrasco Miro (2016) assert that Nigeria is ranked 152 out of 188 independent nations. More than twothirds of Nigeria's population is living in severe poverty, and nearly $50 \%$ of Nigerian women live below the poverty line. In rural areas, most of these women remain. Poor women in Nigeria are more likely to provide their babies with unattended use of informal ANC facilities and use unskilled obstetric treatment at birth compared to their wealthier counterparts.

The use of health care facilities by women from the poorest and the wealthiest families differs (Organization, 2012). Facility-based delivery among poor women has generally been low, averaging 9 
percent since 2003 (Sialubanje et al., 2015). Although approximately 95 percent of women in richer households used skilled ANC in 2013, only one in four poor women received 25 percent ANC from a skilled provider. Among poor women, the use of postnatal care (PNC) is also limited. In 2013, only 14 percent of poor women pursued PNC within 41 days of delivery, compared to 79 percent of wealthier women.

\section{Improving Access to Skilled Birth Attendance}

Between 1990 and 2008, maternal mortality in Nigeria fell from 1,100 to 545 per 100,000 live births and neonatal mortality from 45 to 40 per 1,000 live births. Despite this progress, 33,000 mothers and 241,000 newborns still die yearly, and an estimated 70 to $75 \%$ of these deaths are preventable (Mirzoev et al., 2015). Furthermore, from 2008 to 2013, the maternal mortality ratio did not change significantly. In 2013 , only $60 \%$ of pregnant women in Nigeria attended one or more antenatal visits, and just $38 \%$ of childbirths took place under the supervision of a skilled birth attendant.

According to Findley et al. (2016), to reduce the maternal and mortality rate of new-born in Nigeria, the Subsidy Reinvestment and Empowerment Programme Maternal and Child Health Project (SURE-P MCH) was launched on January 1, 2012, using funds from the removal of subsidies on petroleum. SURE-P MCH consisted of an innovative combination of interventions that target the needs for improved maternal health services. International evidence suggests that both supply and demand factors are a vital influence on health care services utilization. SURE-P MCH was initially launched in 500 public primary health care facilities and their catchment areas, spread across Nigeria's 36 states and the Federal Capital Territory (FCT). This brief describes a non-experimental evaluation of the SURE-P MCH project's impact on access to skilled birth attendance (SBA) and antenatal care (ANC) within the catchment areas of these 500 facilities (Oduenyi et al., 2019).

A mission to cover a thousand primary health centers and their catchment areas throughout 36 Nigerian states and FCT was the SURE-P MCH mission. A programme of strategic objectives to resolve maternal health care problems was carried out in all of these regions. Three main procurement steps were targeted: expansion of primary care facilities, standard equipment and trained midwives to ensure efficient service delivery, the supply of medications, consumables, and other products for reliable maternal and child health services Interventions by SURE-P MCH involved educational practices for the promotion of behavior, maternal well-being and conditional cash transfers (CCT) to pregnant mothers, which were incorporated in a sub-set of organizations.

Chukwuma, Bossert, and Croke (2019), Reported that the Transition Committee of 2015's newly elected president Muhammadu Buhari described the country's most enormous challenges towards achieving sustainable economic growth, public health, and insufficient health facilities. To ensure the pregnancy and childbirth of women in Nigeria are better, it collaborates with development partners, including the UN Population Fund (UNFPA).

\section{Methodology}

A qualitative method applied in a case study research to enhance understanding the policymaking and implementation of a qualitative approach is used (Forester, 1993). Base on the Study's methodological context, thematic analysis procedures followed.

The thematic analysis is a method for the identification, analysis, and reporting of data themes. It gathers and describes the results (Bogdan \& Biklen, 1998). However, it also further defines different aspects of the analysis (Braun \& Clarke, 2006), p.79). This study's data is from a sample of 13 SURE-P desk officers from six (6) selected local governments in Niger State, Nigeria. ((Busarovs, 2013) affirmed that 10,20 or 30 might be engaged in an interview to permit theoretical saturation, which will help minimize the chances of creating a theory based on insufficient data. The selection was based on a purposive sampling technique; in purposive sampling, the researcher controls the subjects; population sampling guarantees accuracy than studying the entire population (Guetterman, 2015). 
In this study, a total of 13 participants were interviewed; all were male, local government officials who were named ad hoc as SURE-P desk officers to organize the implementation of SURE-P across communities in their respective local governments, one of whom was the State SURE-P coordinator responsible for the state-wide implementation of SURE-P.

Data collected during the weekdays and weekends, depending on the participants' convenience to ensure the interviewing of all the participants in this research. However, this study focused on the local government and the state-run SURE-P coordinators, which were the main actors in the implementation of SURE-P in Nigeria's selected local governments. The researcher obtained data using an unstructured interview technique. The researcher first clarified the intent and goal, then obtained the participant's consent for the interviews and the interview's audio recording. The interviews were carried out at the different secretariats of the local governments selected for this study.

The maternal mortality rate viewpoint influenced the interview questions' design, but questions were restricted to variables defined in this perspective. There was some room to explore and probe the SURE-P desk officers' experiences during the interview process. Most of the participants' questions were: what social and economic interventions does the SURE-P target in your LGA? How has the SURE-P impacted on maternal mortality rate in this LGA? How has the SURE-P intervention on primary healthcare centers increase access to medical facilities in this LGA? All the participants spoke in English. All the interviews are recorded and transcribed. The interviews took about 15 to 20 minutes. After transcription, V. Braun and V Clarke (2006) conducted the coding process in line with thematic analysis procedures. Foremost, the researcher familiarized himself with the data generated during the interview. The researcher generated the initial code from the data as the second stage. Thirdly, Themes were searched from the data generated by the researcher. In the fourth stage, the themes generated by the researcher were reviewed. Fifth, the researcher defined, and name themes generated. Finally, the themes made were used to answer the research objective

\section{Result}

The federal government's SURE-P action on primary healthcare in rural communities in Nigeria was intended to ensure that all, particularly pregnant women and children in rural communities in Nigeria, regardless of the region or local government, enjoy equitable access to healthcare facilities and resources to reduce maternal and child mortality rates. The aim was to ensure all Nigerians have access to affordable healthcare from wherever they come.

\section{Primary Healthcare Interventions}

Participants attached substantial importance to SURE-P interventions to improve people's living standards and the communities by providing healthcare services. Many talked about how SURE-P distributed and administered mosquitoes net to control malaria and the infants and maternal motility rate reductions. Healthcare facilities and services were identified by $70 \%$ of participants to have impacted positively on the people and the community especially, the anti-malaria drugs distribution, renovation, and construction of primary healthcare centers, which led to a reduction of maternal motility rate

When the researcher asked one of the participants about his view of the policy, he stated that:

SURE-P programme I can say it is laudable because it improves people's living standards by providing healthcare services in which drugs were administered, mosquitoes' nets distributed to control malaria. Before the SURE-P introduction, people of some communities must travel far to access medical facilities. When SURE-P came, each ward received the construction of primary healthcare. 
From the above findings, the participant's experience revealed that access to necessary medical facilities was challenging. Some of them admit that they must travel a long distance to access healthcare services. This, however, is partly responsible for the rise in the mortality rate of the selected local government before SURE-P introduction

The participants from lavun local government reaffirmed that the intervention by SURE-P on quality healthcare and access to quality medical facilities is meant to improve the quality of lives across the communities as part of measures to cushion the pains of subsidy removal on the people by reinvesting the proceeds to provide the critical infrastructures at rural communities. In Nigeria, particularly, Niger state, the SURE-P interventions are in all local governments so that no area is neglected. Specifically, one participant stated:

I can say that the coming of SURE-P has come with many benefits to this community, especially in the areas of increasing access to healthcare facilities because SURE-P builds new and renovate some primary healthcare centers. Each ward across local governments received a new primary healthcare center to increase access to our people

(P3-Lavun Sure-p Desk Officer I)

The socio-economic intervention of SURE-P on quality healthcare provision to rural communities in Nigeria is undoubtedly meant to ensure increased access to quality medical facilities and healthcare to all communities. According to the findings of this study. One of the respondents from Chanchaga local government stated:

I can say that the intervention of SURE-P has impacted well because mosquitos' nets were given to pregnant women and the children to control the mortality rate in the communities, we don't have to go to cities for medical attention.

(P6-Chanchag Ward Development Officer)

Table 1: Maternal mortality rate (2016-2019)

\begin{tabular}{llllll}
\hline Local Gov'ts & $\mathbf{2 0 1 3}$ & $\mathbf{2 0 1 4}$ & $\mathbf{2 0 1 5}$ & $\mathbf{2 0 1 6}$ & Total \\
\hline Bida & 43 & 22 & 23 & 23 & 111 \\
Lavun & 32 & 12 & 20 & 18 & 82 \\
Chanchaga & 58 & 12 & 21 & 19 & 110 \\
Bosso & 56 & 28 & 22 & 19 & 126 \\
Kontagora & 35 & 22 & 17 & 15 & 89 \\
Wushishi & 21 & 13 & 14 & 13 & 61 \\
\hline
\end{tabular}

Source: Niger State Hospital Information Management Unit

Table 2: Maternal mortality rate (2016-2019)

\begin{tabular}{llllll}
\hline Local Gov'ts & 2016 & 2017 & 2018 & 2019 & Total \\
\hline Bida & 3 & 16 & 14 & 6 & 39 \\
Lavun & 2 & 11 & 13 & 8 & 33 \\
Chanchaga & 0 & 30 & 13 & 7 & 33 \\
Bosso & 4 & 30 & 13 & 3 & 50 \\
Kontagora & 6 & 13 & 12 & 7 & 38 \\
Wushishi & 2 & 9 & 6 & 7 & 24 \\
\hline
\end{tabular}

Source: Niger State Hospital Information Management Unit 

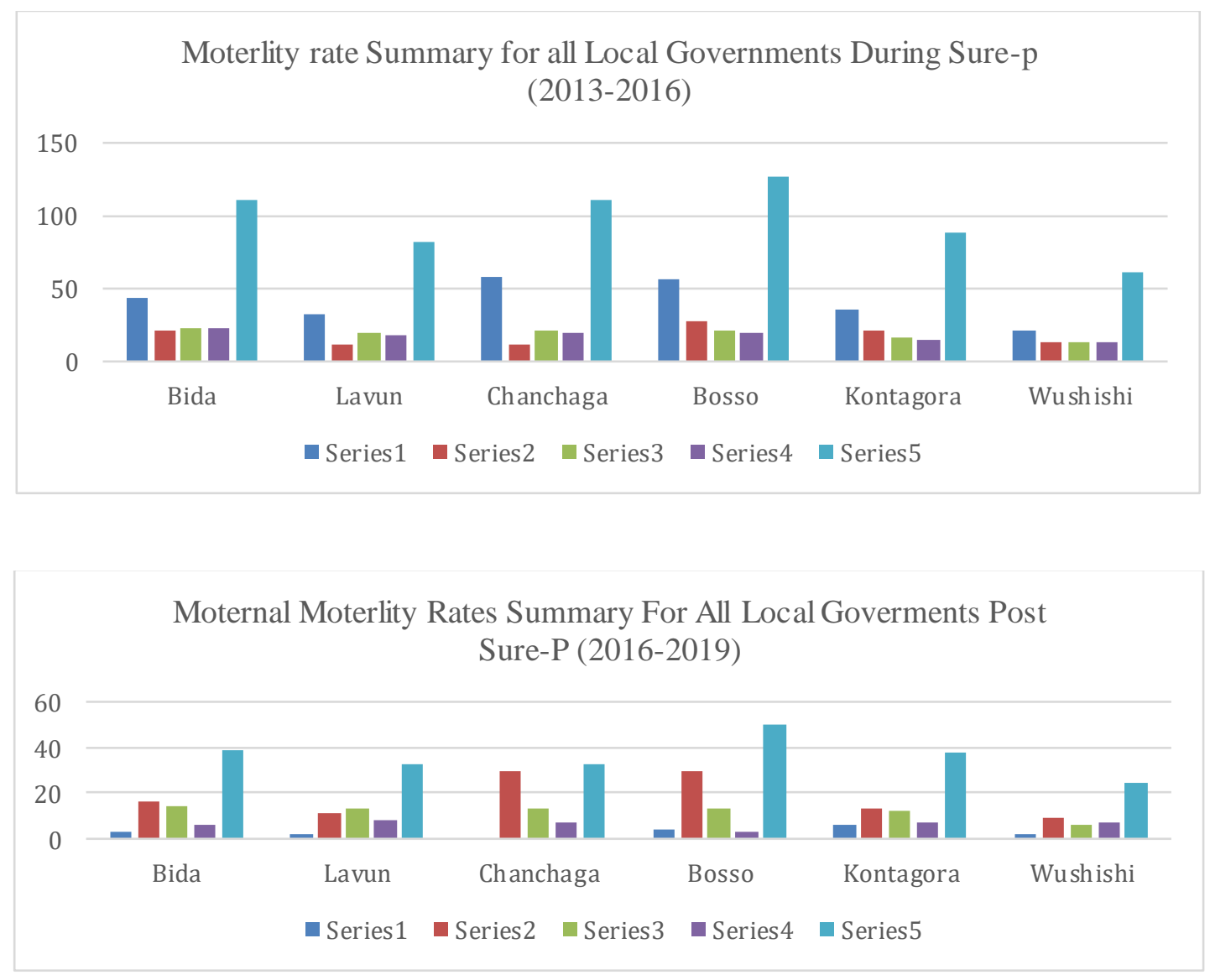

The above tables are the statistics of motility rates from the Niger state hospital information management unit for the (6) selected local government of this Study. The statistics support the claims of the participants. The majority of the participants, when responding to a question by the researcher on how the socio-economic interventions of SURE-P impacted people and communities in their LGAs, the participants explained the SURE-P intervention impacted through the provision of healthcare facilities and services to communities in their local governments. They stated that new primary heal thcare centers had been built in their communities and some renovated.

The finding also reveals that most of the participant's experience shows that community members have also given mosquito nets free of charge.

Findings from the above statistics reveal that the SURE-P intervention in primary healthcare significantly impacted the communities' motility rate in the selected local government. The statistics show that the motility rate in Bida local government which was 111 between the period the federal government of Nigeria introduced the SURE-P, which build new hospitals and primary healthcare centers have been built, and some renovate in the year 2013 - 2016, and by October 2016- 2019 when the SURE-P was scrapped, the healthcare centers are fully operational, the motility rate for Bida local government went down drastically 39 the statistics show that the motility rate for Lavun local government dropped down from 82 to 33 the rate for Chanchaga dropped down from 110 to 50 the rate for Bosso diminished from 126 to 50 that of Kontagora fall from 89 to and the motility rate for wushishi which was 61 dropped to 24 This, therefore, shows the SURE-P intervention has made a significant impact on reducing the motility rate of the selected local governments of Niger state, Nigeria

\section{Conclusion and Implications}

The article explores the impact of SURE-P implementation on primary healthcare intervention and maternal mortality reduction among the selected local government areas of Niger State, Nigeria. The 
results revealed that the SURE-P intervention on primary healthcare had improved access to healthcare across the communities to the most disadvantaged groups and reduced healthcare access gaps. The study's findings also show that maternal mortality rates have reduced due to the implementation of SURE-P interventions. The results reveal that low access to primary healthcare before the introduction of the SURE-P gave rise to the maternal mortality rate of these local governments. Results show that increasing access to primary healthcare facilities following the SURE-P intervention has improved the communities' general well-being in the selected local government areas. The study concludes that if the primary healthcare SURE-P intervention is maintained and adequately supported, it would lead to a significant rise in maternal and child well-being, a decline in mortality rates, and a drop in maternal mortality inequalities in these local government areas. And other parts of Nigeria.

On the grounds of this study's limitations, we would like to suggest that this study's focus be broadened by increasing the case study's coverage or re-conducted in other areas using the same sample or, consequently, utilizing a quantitative methodology.

\section{Recommendations}

Therefore, we make the following recommendations based on the results of this report. That the government must have more primary health centers and professional health workers in the local government's designated areas to allow them to deliver essential health services effectively, it is also essential to enhance referral facilities so that situations that may not be treated at the primary level of healthcare are immediately forwarded to the next level. Policymakers should create policies to promote multi-sectoral investments in infrastructure, roads, electricity, and education for women to further expand women's access to and accept health services. There is proof that engaging in women's education will improve maternal well-being and lower maternal mortality. Malaysia and Sri Lanka had intentional policies aimed at encouraging women's literacy that stressed the value of educating women and maternal health.

Also, the health sector in Nigeria needs to be strengthened by, among other things, increasing funds for health care, allowing better use of resources, upgrading infrastructure, and reducing the expense of health services

\section{References}

Adewuyi, E. O., Auta, A., Khanal, V., Bamidele, O. D., Akuoko, C. P., Adefemi, K., Zhao, Y. (2018). Prevalence and factors associated with underutilization of antenatal care services in Nigeria: A comparative study of rural and urban residences based on the 2013 Nigeria demographic and health survey. PloS one, 13(5), e0197324.

Akinola, A. O. (2018). Oil subsidy crises in Nigeria: lessons from developing countries. AFFRIKA Journal of Politics, Economics and Society, 8(1), 53-78.

Akpan, N. S. (2012). From agriculture to petroleum oil production: What has changed about Nigeria's rural development? International Journal of Developing Societies, 1(3), 97-106.

Amakom, U. (2013). Subsidy Reinvestment and Empowerment Programme (SURE-P) Intervention in Nigeria: An Insight and Analysis.

Boas, T. C., \& Gans-Morse, J. (2009). Neoliberalism: From new liberal philosophy to anti-liberal slogan. Studies in comparative international development, 44(2), 137-161.

Bogdan, R., \& Biklen, S. (1998). Introduction to qualitative research in education. England: Pearson.

Braun, V., \& Clarke, V. (2006). Using thematic analysis in psychology. Qualitative research in psychology, 3(2), 77-101.

Busarovs, A. (2013). Rally Fighter, Crowd designed vehicle, case study of open innovation. Paper presented at the ISPIM Conference Proceedings.

Carrasco Miro, G. (2016). United Nations Africa Human Development Report 2016: Accelerating Gender Equality and Women's Empowerment in Africa. In: United Nations Development Programma (UNDP). 
Chomsky, N. (1999). Profit over people: Neoliberalism and global order: Seven Stories Press.

Chukwuma, A., Bossert, T. J., \& Croke, K. (2019). Health service delivery and political trust in Nigeria. SSM-population health, 7, 100382.

Dahiru, T., \& Oche, O. M. (2015). Determinants of antenatal care, institutional delivery and postnatal care services utilization in Nigeria. Pan African medical journal, 22(1).

Enfield, S. (2019). Gender Roles and Inequalities in the Nigerian Labour Market.

Filippi, V., Ronsmans, C., Campbell, O. M., Graham, W. J., Mills, A., Borghi, J., . . Osrin, D. (2006). Maternal health in poor countries: the broader context and a call for action. The Lancet, 368(9546), 1535-1541.

Findley, S., Afenyadu, G., Okoli, U., Baba, H., Bature, R., \& Mijinyawa, S. (2016). Implications of the SURE-P MCH National Village Health Worker Experience in Northern Nigeria for the Road Map for Village Health Workers in Nigeria. J Community Med Health, 6(419), 21610711.1000419 .

Forester, J. (1993). Critical theory, public policy, and planning practice: SUNY Press.

Guetterman, T. C. (2015). Descriptions of sampling practices within five approaches to qualitative research in education and the health sciences. Paper presented at the Forum qualitative Sozialforschung/forum: qualitative social research.

Harvey, D. (2005). A Brief History of Neoliberalism (New York and Oxford: Oxford University Press). From a whisper to a scream.

Ikpeazu, A. E. (2018). Can the Midwives Service Scheme (MSS) present an effective and health systems strengthening response to the shortages in human resources for maternal health services in Nigeria? , London School of Hygiene \& Tropical Medicine,

Kim, E. T., Singh, K., Speizer, I. S., Angeles, G., \& Weiss, W. (2019). Availability of health facilities and utilization of maternal and newborn postnatal care in rural Malawi. BMC pregnancy and childbirth, 19(1), 503.

Lamina, M. A. Prevalence of abortion and contraceptive practice among women seeking repeat induced abortion in Western Nigeria. Journal of pregnancy, 2015.

Mercer, A., Haseen, F., Huq, N. L., Uddin, N., Hossain Khan, M. \& Larson, C. P. (2006). Risk factors for neonatal mortality in rural areas of Bangladesh served by a large NGO programme. Health policy and planning, 21(6), 432-443.

Mirowski, P. (2009). Defining neoliberalism. The road from Mont Pèlerin: The making of the neoliberal thought collective, 417-450.

Mirzoev, T., Etiaba, E., Ebenso, B., Uzochukwu, B., Manzano, A., Onwujekwe, O., . . . Newell, J. (2015). Study protocol: realist evaluation of effectiveness and sustainability of a community health workers programme in improving maternal and child health in Nigeria. Implementation Science, 11(1), 83.

Oduenyi, C., Ordu, V., \& Okoli, U. (2019). Assessing the operational effectiveness of a maternal and child health $(\mathrm{MCH})$ conditional cash transfer pilot programme in Nigeria. BMC pregnancy and childbirth, 19(1), 298.

Okoli, U., Morris, L., Oshin, A., Pate, M. A., Aigbe, C., \& Muhammad, A. (2014). Conditional cash transfer schemes in Nigeria: potential gains for maternal and child health service uptake in a national pilot programme. BMC pregnancy and childbirth, 14(1), 408.

Onokerhoraye, A. G., Omuta, G. E., Okonofua, F., Obanovwe, G., Isah, E., Okoro, F., \& Onojeta, F. (2014). Perspectives on Primary Health Care in Nigeria: Past, Present and Future.

Onyishi, A. O., Eme, O. I., \& Emeh, I. E. J. (2012). The domestic and international implications of fuel subsidy removal crisis in Nigeria. Kuwait Chapter of Arabian Journal of Business and Management Review, 33(835), 1-24.

Organization, W. H. (2012). Malaysia health system review. In: Manila: WHO Regional Office for the Western Pacific.

Sialubanje, C., Massar, K., van der Pijl, M. S., Kirch, E. M., Hamer, D. H., \& Ruiter, R. A. (2015). Improving access to skilled facility-based delivery services: Women's beliefs on facilitators and barriers to the utilisation of maternity waiting homes in rural Zambia. Reproductive health, $12(1), 61$.

Yaya, S., Okonofua, F., Ntoimo, L, Kadio, B., Deuboue, R., Imongan, W., \& Balami, W. (2018). Increasing women's access to skilled pregnancy care to reduce maternal and perinatal mortality 
Malaysian Journal of Social Sciences and Humanities (MJSSH), Volume 5, Issue 11, (page 245 - 256), 2020

DOI: https://doi.org/10.47405/mjssh.v5i11.543

in rural Edo State, Nigeria: a randomized controlled trial. Global Health Research and Policy, 3(1), 12. 